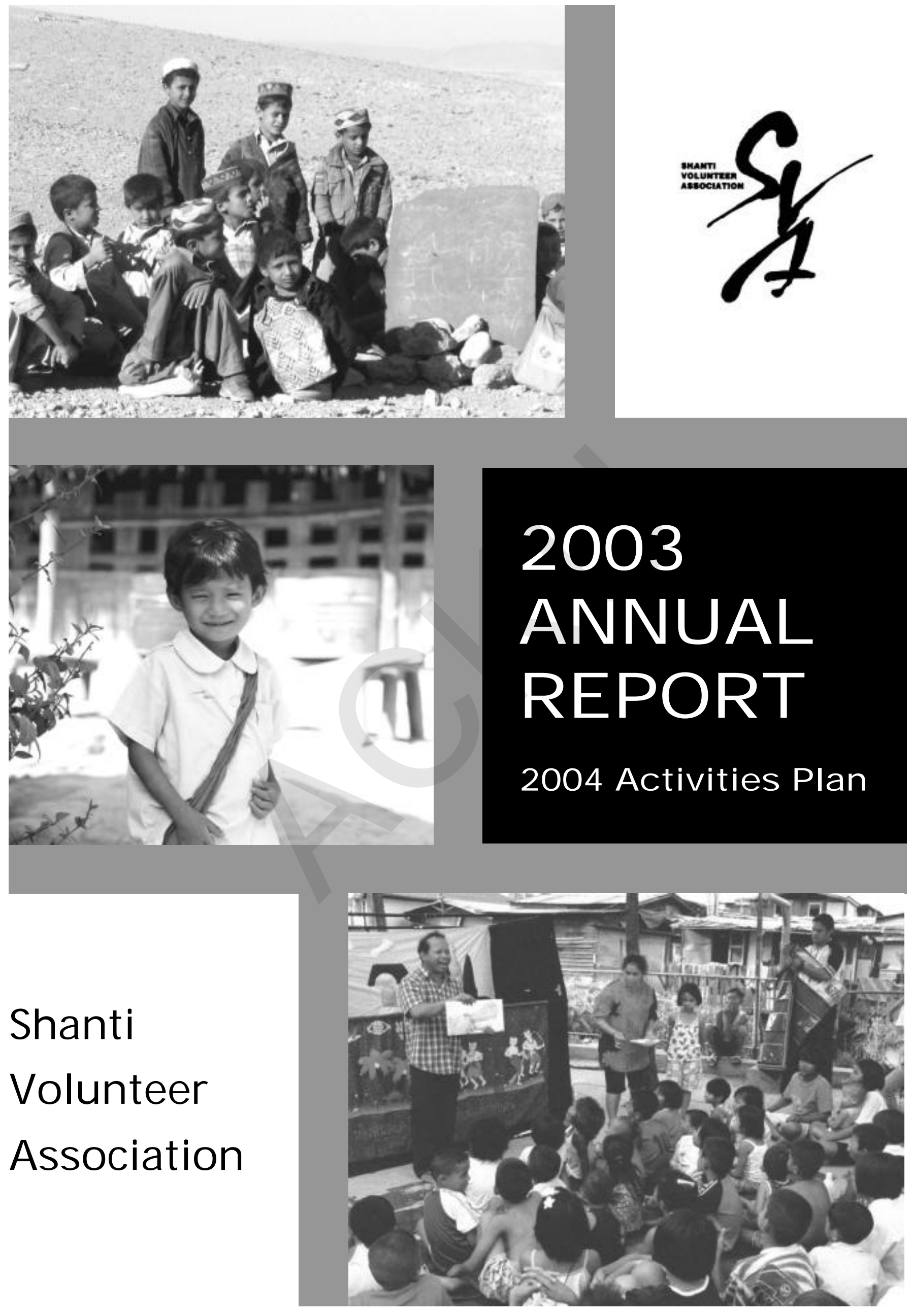




\section{Greetings from the President}

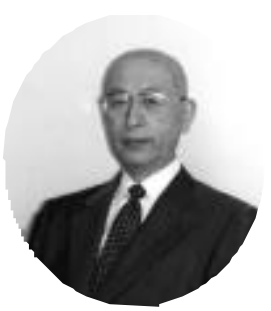

Reviewing the past activities of SVA, one must acknowledge with appreciation the great cooperation extended by our supporters in the past year, making possible our support to the children of the world.

The ultimate goal of SVA is to seek serenity (peace) on earth. Serenity on the earth (peace to the world) is a common desire of everyone, but has not yet become a reality. One might think, perhaps, it is too enormous and preposterous a wish.

When we heard about the launching of retaliatory attacks by the U.S. military forces in Afghanistan, and then the aerial bombing of Iraq, SVA declared its opposition to the war. Regretfully, however, our declaration was still a small voice, and even the worldwide opposition did not change their minds, with the attacks continuing. The people of the world are well aware that armed conflict causes distress to many people, and it takes time to recover from the scars of war. Even in Japan, after 60 years without war, there are still many people who are tormented by the aftereffects of the atomic bombs.

The history of the human race is said to be a history of strife. But at the same time, war has also contributed to the development of scientific culture and satisfied human desire. Nevertheless, as war starts from human desire, its consequences cannot be justified.

The most important thing we must do in the current world situation is to exert ourselves to pass on the earth in sound condition to the children of the next generation. Based on this principle, SVA plans to help the children of the world as much as possible through educational support.

It is the objective of all SVA activities and our perpetual principle to "Live Together and Learn Together". It is my sincere wish to pray together with you for the emergence of world peace.

June 2004

\section{Zendou Matsunaga}

\section{President}

Shanti Volunteer Association (SVA)

\section{Contents:}

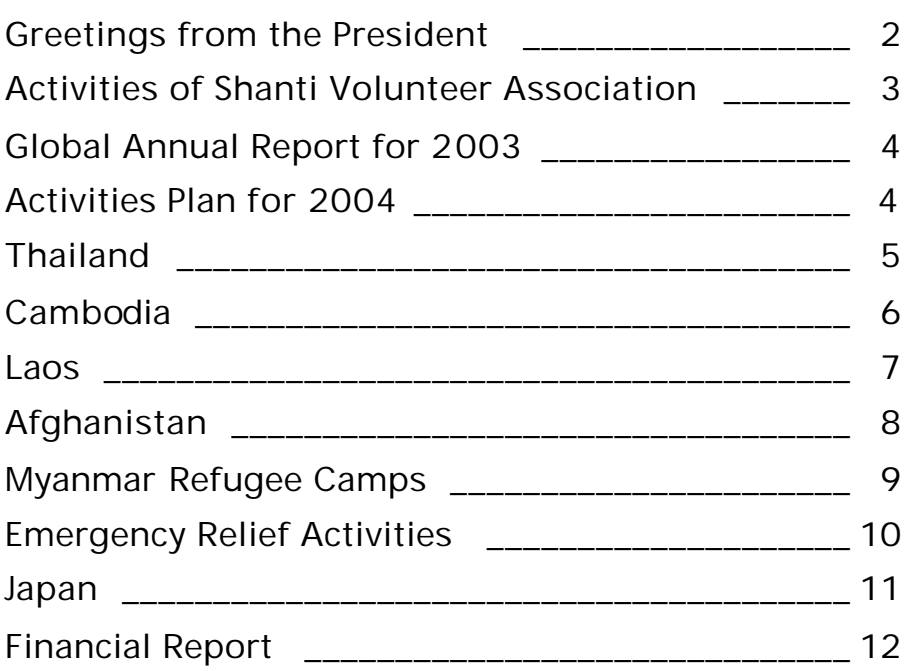

\section{History of SVA}

1980 Japan Sotoshu Relief Committee (JSRC), antecedents of SVA, was established. JSRC opened office in Bangkok. Thailand and commenced mobile library services to Cambodian refugee camps. Then, JSRC opened printing unit and permanent libraries in Sakeo refugee camp.

1981 Volunteers of JSRC established Sotoshu Volunteer Association (SVA).

1983 Campaign to donate clothing was developed in several places in Japan.

1984 First development project was commenced in Baan Sawai village, Surin province, Thailand. SVA was awarded Shoriki Matsutaro Award.

1985 Printing project commenced at Ban Vinai refugee camp in Thailand. SVA also commenced library activities at Chiang Khan district in Loei province and Suanphlu slum in Bangkok. SVA received the Soroptimist Japan Foundation Award.

1986 SVA received the Ministry of Foreign Affairs of Japan Award.

1989 SVA opened vocational training center at Klong Toey slum in Thailand.

1991 SVA opened office in Phnom Penh, Cambodia.

1992 SVA established Sikkha Asia Foundation, local subsidiary of SVA in Thailand. SVA opened office in Vientiane, Laos. The name of organization was changed to Sotoshu International Volunteer Association (SVA).

1994 SVA was awarded the Mainichi International Exchange Award by the Mainichi Newspaper.

1995 SVA undertook relief activities for the victims of the Hanshin/Awaji great earthquake. SVA received a letter of appreciation from the head of Toshima Ward, Tokyo.

1996 SVA served as the secretariat of the Japan NGO Forum for HABITAT II, and participated in international conferences as a representative of Japanese NGOs.

1997 SVA donated relief foodstuffs to the Democratic People's Republic of Korea. SVA organized Shokichi Kina charity concert at Sojiji Temple in Yokohama. Tokyo office was moved from Sugamo to Daikyocho, Shinjuku-Ku.

1998 SVA organized "Shinjuku Asia Festival."

1999 SVA was registered with the Ministry of Foreign Affairs as a public association and renamed as Shanti Volunteer Association (SVA.) SVA undertook relief activities for the victims of great earthquakes in Turkey and Taiwan.

2000 SVA started library activities for refugees from Myanmar (Burma) in Thailand. Rev. Jitsujo Arima, former executive director of SVA, passed away.

2001 SVA undertook relief activities for the victims of earthquake in western India. SVA undertook emergency food support to Afghan refugees in Afghanistan and Pakistan.

2002 First "SVA Day" celebrated. Kazuhiro Sasaki, then with Seattle Mariners and now with Yokohama Baystars professional baseball club, was nominated SVA goodwill ambassador. 


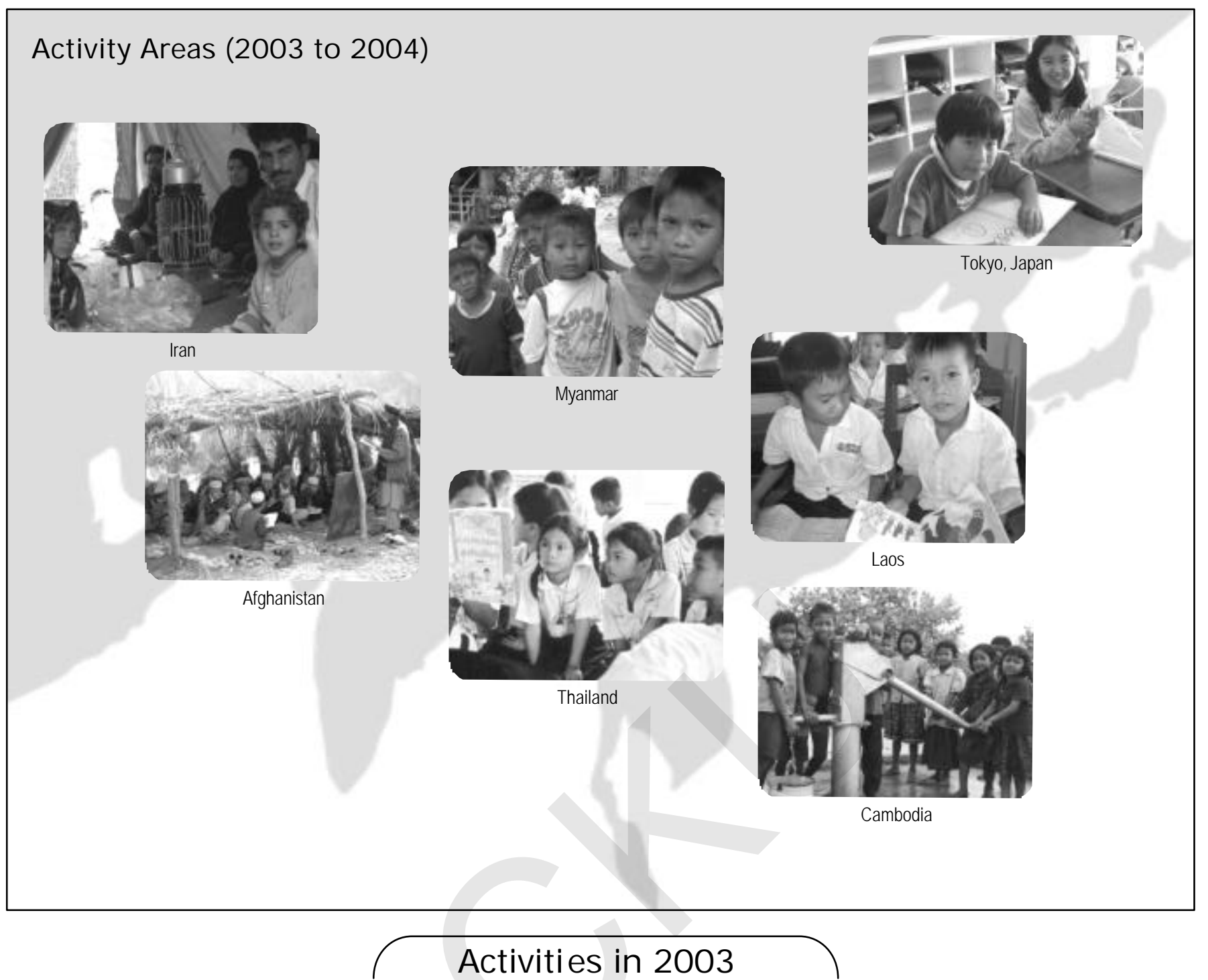

January Educational Support Activities in Afghanistan commenced. Nursery school opened in Santisuk village of Phayao province (Thailand). "Buddhist NGO Network" established. Two staff of Mae Sod office (Thailand) visited Japan for meetings at several places.

February Picture books collected under "Books for Children Campaign" were shipped to Laos and Cambodia. "Statement requesting immediate cease-fire of the armed attack in Iraq" issued. Seminar on "Settlement of Confrontation and Working Off the Trauma" held at the Myanmar Refugee Camps. New accommodation completed for Khokmuang Village nursery school, Surin Province (Thailand).

March General Assembly for 2003 convened. Washed-away library No.2 of Myanmar Refugee Camp at Mae Kong Ka was rebuilt.

April Jalalabad office (Afghanistan) opened. National storytelling contest held in Cambodia.

June Staff of Afghanistan office trained at the offices in Thailand and Cambodia. Monitoring carried out on the relief activities for the great earthquake and riot (June 2001) in Gujarat, India. "Regional Supporters Assembly" held in Nagano prefecture. "Disaster Prevention Training for Children" held at Matsumoto city, Nagano prefecture.

July SVA staff dispatched to help relief activities after the earthquake in the northern Miyagi prefecture. Three staff of library activities at Cambodia office visited Japan for meetings at several places.

September Savannaket (Laos) Provincial Library opened. Education Environment Improvement Project (a joint development project with JICA) finished.

October "SVA Kinki Assembly" held in Osaka. The 8th Asian Children's Cultural Festival held in Thailand.

November $\quad 170,000$ items of winter cloth ing shipped to the Myanmar Refugee Camps. SVA accredited as a Public Service Corporation by the Ministry ofForeign Affairs.

December Ordinary Delegates Assembly convened. "SVA Day" - Commemoration in the publication of "Serenity on the Earth". Distribution project of mimeograph printers completed in Laos - commemoration held. Emergency relief activities offered to the victims of the great earthquake in southeastern Iran. 


\section{GLOBAL ANNUAL REPORT FOR}

\section{3}

The year 2003 was marked by the posthumous publication of writings by the late Rev. Jitsujo Arima who was the core leader in the founding of SVA. A function to remember his achievements and to launch the publication was held, with many guests from various fields in attendance. The gathering reinforced the principles with which SVA has grown, and provided us an occasion to reaffirm our future direction as an NGO.

In 2003 we established our office in Afghanistan, deviating from our tradition of focusing SVA support on the Southeast Asian region, and commenced educational support activities for the Afghan people in cooperation with a regional NGO. In our long-established offices in Thailand, Cambodia and Laos, we discussed with the regional staff of each country the possibility of autonomy in management control. We all agreed to this concept in principle and to continue discussions on this as one of our most important matters.

In domestic activities, of the purpose of further improving the relationship between members, supporters and staff, we held an assembly in Nagano for nationwide members and another in Osaka for the members of Kansai area.

In addition, supporters for "Books for Children Campaign" and "Recycle Books Aid" (projects that are becoming increasingly popular as a home-based way of participating in international cooperation) have increased as the result of positive participation by business enterprises and trade unions. In particular, for the affixing work to picture books, many primary, middle and high school students have participated during their "Today's World" class. This campaign is becoming popular as a step towards international understanding.

With emergency relief activities, considerable effort has been placed on the upgrading of guidelines for domestic or overseas disasters, and the stepping up of networking relief systems for urban disasters.

In order to cope with the increasing complexity of the accounting system at the Tokyo office, the Accounting and General Affairs Section has taken a leading role in developing a system to streamline the transfer system for budgets and subsidies between the Tokyo office and overseas offices. Since 2001 an independent auditing house, Shin Nihon \& Co., has audited our accounts and, with their support, we are trying to make an accurate report collating with that of our internal audit.

One noteworthy event occurred in November when the Ministry of Foreign Affairs, which authorizes preferential measures to exempt donations from income and corporate taxes, accredited SVA as a public service corporation.

In order to make organizational management more intelligible and also to strengthen the secretariat, the structure of the Board of Directors has been reorganized, and a Board of Executive Directors has been established for the purpose of accelerating activities and to support the secretariat. According to the new strucure, each director will become responsible for one of the activities of either overseas, domestic, emergency relief or religious organization co-operation, and take part in planning or discussion for new projects.

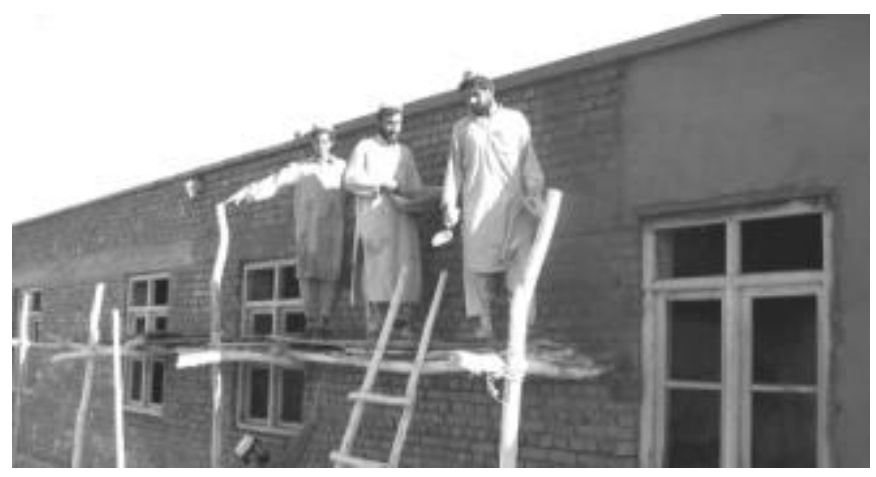

School construction in Afghanistan

\section{4 actiriss Pan}

Since we were organized as a juridical corporation, the circle of support for SVA has continued to spread among business enterprises, organizations and individuals; and through the participation of these supporters we wish our activities as an NGO to expand both domestically and internationally. At the same time, we wish to further reinforce the links between members and supporters in each region.

On the activities, we will investigate the regions or projects that need our participation and will support them enthusiastically. On the administrative control of the office, we will cope with problems more affirmatively. And in regard to the financial situation, we will try to improve income and expenditure by analyzing current circumstances to reach the target figures.

On the management of overseas offices, we will continue to seek a course for autonomy in administrative control by regional staff, and to improve the level of their ability. At the same time, we will investigate potential new projects in which we can participate, and to which we can extend as much assistance as possible. The Board of Directors will discuss future visions for overseas offices within this year.

In regard to support for Afghanistan, which has now passed two years, there are still unclear factors on the future direction of the country. Therefore, we plan to continue the project paying more attention to risk management.

Ever since its foundation, the activities of SVA have relied on the cooperation of members and supporters. Bearing this in mind, we wish to investigate new projects in which we can participate with members and supporters. At the same time, we wish to support new leaders of the next generation from the cooperative organizations in the regions, and provide them with more opportunities for "on the spot training" to nurture more capable people.

Meetings of the Board of Executive Directors and of each responsible section manager will be convened periodically in order to discuss matters relevant to the administration, projects, financing and others. The secretariat will take seriously the recommendations or suggestions adopted at the meetings for implementation.

We plan to take educational support activities as a core activity this year, and set up a midterm target for creating more effective activities. 


\section{OVERVIEW:}

The Thaksin administration, which has set as policy priorities the eradication of poverty, corruption and narcotics, is also enforcing several policies with significance to education and children's rights throughout the country. But the Sub-committee on the Rights of Juveniles, Youth and Family of the National Human Rights Committee of Thailand reported that juvenile prostitution, trafficking of children, juvenile labor and ill-treatment of children were serious problems among the nation's 26.73 million children, and also indicated an increase in the number of abandoned children, street-children and children lured into crime.

In 2003, Sikkha Asia Foundation, a regional juridical organization, carried out training of Thai staff directed towards autonomy of the organization. In 2004, we plan to make library, scholarship/dormitory and interchange/seminar activities our three priority activities, and plan to expand the current activity sites of Bangkok, Baan Sawai (Surin), Chiang Khan (Loei) and Pong (Phayao).

\section{LIBRARY ACTIVITIES:}

In addition to the operation of permanent libraries, we have focussed on the mobile libraries as well as training for nursery staff and schoolteachers on utilizating the library. We carried out nine trainings in Bangkok, Phayao and Mae Sariang, and 510 teachers attended.

The mobile units made 283 tours to city slums, nursery schools in rural villages and Myanmar refugee camps, with 57,369 people visiting the units. The total number of visitors to the libraries was more than 160,000 . Following the acceptance of trainees from Sri Lanka a year ago, five Thai staff members were sent to Sri Lanka for an eightday seminar.

It must be noted that, in 2003 , the networking of library activities was instituted in the nursery schools in Phayao and Surin. For the 2004 plan, the nursery school project (which was a part of the community support project) will be integrated into the library activities. It will carry out a three-year human nurturing project focusing on storyelling for nursery school teachers in Bangkok, Phayao, Surin, Loei and new regions (proposed sites Chiang Mai and Nakhon Ratchasima) to promote networking for improvement of pre-school education.

\section{DORMITORIES ACTIVITIES:}

Dormitories activities serve the needs of middle and high school students from remote areas in Pong (Phayao) and Chiang Khan (Loei) who have difficulty in attending school due to distance and poverty reasons. The number of boarders in 2003 is shown. Boarders in the dormitory at Baan Sawai (Surin) had to return to their homes and, therefore, the dormitory project was temporarily suspended. In Chiang Khan, a new project (Project Y) was inaugurated, for which 11,360 square metres of farmland was acquired.

Number of Boarders at Each Dormitory in 2003

\begin{tabular}{|c|c|c|c|c|}
\hline Area & Name & $\begin{array}{c}\text { Middle } \\
\text { School } \\
\text { Students }\end{array}$ & $\begin{array}{c}\text { High } \\
\text { School } \\
\text { Students }\end{array}$ & Total \\
\hline Loei & $\begin{array}{c}\text { Chiang Khan Dormitory } \\
\text { (Mekong Home for } \\
\text { Youth) }\end{array}$ & $20(20)$ & $10(9)$ & $30(29)$ \\
\hline Phayao & $\begin{array}{c}\text { Shanti Students } \\
\text { Dormitory }\end{array}$ & $17(7)$ & $31(16)$ & $48(23)$ \\
\hline
\end{tabular}

( ) = female students
In 2004, we plan to continue he present activities and combine the interchange/training activities with the utilization of the farmlands attached to the dormitories.

\section{ASIAN SCHOLARSHIP ACTIVITIES:}

Details of scholarship activities we carried out in 2003 for children from Bangkok slums, minority people from highland regions of the north and farming villages of the northeast regions, are shown hereunder. In 2003, we succeeded in reviewing our program on the territory allocation, expedited reporting by temporary translators and revised our project management system. On the other hand, it was difficult to recruit sponsors in Thailand.

Scholarship Recipients in 2003

\begin{tabular}{|c|c|c|c|c|}
\hline Region/ Level & $\begin{array}{c}\text { Middle } \\
\text { Schools }\end{array}$ & $\begin{array}{c}\text { High } \\
\text { Schools }\end{array}$ & Colleges & Total \\
\hline Bangkok & $47(28)$ & $15(13)$ & $3(2)$ & $65(43)$ \\
\hline Surin & $63(47)$ & $33(25)$ & $4(3)$ & $100(75)$ \\
\hline Loei & $58(14)$ & $31(23)$ & $2(1)$ & $91(38)$ \\
\hline Phaya0 & $49(35)$ & $33(20)$ & $14(6)$ & $96(61)$ \\
\hline Total & $217(124)$ & $112(81)$ & $23(12)$ & $352(217)$ \\
\hline \multicolumn{5}{|c}{$(\quad)=$ female students }
\end{tabular}

In 2004, taking into consideration the yearly increase of applicants, we plan to increase the number of scholarship recipients by 100 . We also plan to organize a tour for the Japanese sponsors to meet their scholarship recipients.

\section{INTERCHANGE/TRAINING ACTIVITIES:}

The number of visits to our Bangkok office in 2003 was 774 visitors in 178 groups. This represented a decrease to around half the previous year's level, and was due to the spread of SARS. This has greatly affected the interchange/training and craft activities. The intern program, which has been implemented since 2002, was well received, with seven people participating in 2003. In October 2003, the Asian Children's Cultural Festival, International Camp and Thai Youth Seminar were successfully held in cooperation with the ASEAN Foundation, with a total of 227 children from eight countries participating.

In 2004, we will strive to restore the interchange/training activities to previous levels, and in October we plan to hold the Asian Children's Cultural Festival, focusing on the camp.

\section{VOCATIONAL TRAINING PROJECT}

(Independent operation by Sikkha Asia Foundation):

In 2003, we continued the printing operation and the sewing and leather craft operations at work centers to gain additional income. In 2004, we will try to canvass for more orders in Thailand and improve quality in printing/publication and leather craft, as well as strive for better marketing.

\section{COMMUNITY SUPPORT PROJECT}

(Independent operation by Sikkha Asia Foundation):

The problem of narcotics, mainly stimulants, in the villages is serious and we have implemented a promotional campaign in cooperation with local residents and schools. In particular, several meetings were held for young people and, in connection with the campaign, we have implemented a reforestation project. The recycled soap project, which we started in connection with the recycle campaign, has become very popular and we have opened 35 workshops with 130 participants. We plan to continue the campaign in 2004. 


\section{CAMBODIA}

\section{OVERVIEW:}

2003 was the 50th year since diplomatic relations between Japan and Cambodia were established. Related celebrations and events were held at several places in Cambodia, heightening the friendly relationship between the two countries. In July 2003, an election for members of the national assembly was held without any trouble, with 30,000 election supervisors from Cambodia and overseas overseeing the balloting. But negotiations to organize a coalition cabinet among the Cambodian People's Party, Funcinpec Party and Sam Rainsy Party have not come to agreement des pite mediation by the king; thus a new cabinet has not yet been formed.

For the Phnom Penh office, 2003 was the last year of a 3-year plan starting in 2001. We tried to transfer operations to the Cambodian staff as much as possible and to manage each project comprehensively and efficiently. Furthermore, we are implementing evaluations of the cultural activities, library activities and school construction activities. With the results of the evaluations, we will try to strengthen the details of the activities and will commence new projects in new areas in 2004.

\section{FUNDAMENTAL EDUCATION SUPPORT ACTIVITIES:}

\section{(1) Library Project:}

We have collected vanishing Cambodian folktales and published them in five titles of picture books (3,000 copies each), two titles of picture story cards (350 sets each), and reprinted four titles of picture books (3,000 copies each). They were distributed through "Seminar on Storytelling \& Library Activities". We sponsored 2 seminars (150 participants) and the Provincial Bureau of Education sponsored 2 (86 participants). In the provinces of Kompong Chhnang, Takeo and Kampot, where trainings for the library staff were already completed, three-day refresher courses were provided for 478 staff. We also organized study tours for the school principals and library staff of Veal Veng district of Pursat province, which was once dominated by the Khmer Rouge, to other districts where library activities are being carried out. Further, we have carried out evaluations of activities in Phnom Penh city and the provinces of Takeo and Kandal where training of the library staff has already been completed.

In 2004, we plan to implement the following projects:

1. "Seminar on Storytelling and Library Activities" in the provinces of Battambang, Banteay Meanchey and Kompong Thom. In the provinces of Kompong Chhnang, Svay Rieng and Pursat, we plan to carry out postevaluations.

2. We will publish 14 titles of picture book in the Khmer language and picture story cards, reprint picture books, and will collect more folktales to preserve them.

3. Carry out mobile library project in primary schools and slums.

\section{(2) School Construction Project:}

We have selected proposed sites for school construction and postevaluation, in cooperation with the library activities section. Seven 5-classroom buildings and three 3-classroom buildings have been constructed as primary schools. A toilet room and well were annexed to each school building and, at the same time, a seminar for students and teachers on the use of the toilet room was held at each school in order to create awareness of sanitation. Postevaluations are being carried out at all schools constructed after 1991. We are also promoting the necessity of school construction, carrying out coordination work with the Ministry of Education and exchanging information with other organizations.

In 2004, Kompong Thom province (where battles raged up until 1997) will be our new target area for the construction of five 5-classroom buildings and eight 3-classroom buildings. We will also change materials and equipment at the schools to improve suitability and quality, and install ramps for the disabled children.

\section{(3) Asian Children's House Project:}

We nurtured 141 children at the kindergarten affiliated with the kindergarten teacher's training school, the only school of its type in Cambodia. The number of visitors to the permanent library was 4,959, whereas mobile libraries toured slums and 25 kindergartens in Phnom Penh city and received 3,841 visitors. We have supported the dormitory expenses of 104 students at the kindergarten teachers' training school. A re-training course for teachers was provided at three places with 160 people participating and refresher courses were held twice with 210 participants. A final combined evaluation meeting with the headquarters of JICHIRO (All Japan Prefectural and Municipal Workers Union) was convened.

In 2004, we will offer small-scale support for the project's transition to the Ministry of Education that is scheduled for the end of 2005. Activities we are going to support will be: Scholarships for kindergarten children; Repair and purchase of training materials for the permanent library; Advice and technical support for the seminar on publishing picture books, and their use with infants.

\section{CULTURAL SUPPORT ACTIVITIES:}

We held the seminars "Buddhism and Social Development" in Pursat province, and "The Teaching of Buddhism and its Practice" in Kampot province, with about 400 priests and temple committee members attending each seminar. In the provinces of Takeo and Prey Veng, we conducted postevaluations of seminars. We reprinted three titles, totaling 45,000 copies, of Buddhist books in the Cambodian language, and completed distribution of the books to 4,060 temples and 1,446 Buddhist schools.

In 2004, we plan to implement: Distribution of reprinted books on Buddhism and Cambodian culture and follow-up monitoring at the receiving temples; Opening of a seminar on Buddhism and social development; Quality improvement of activities based on the results of the evaluation; and Feasibility study on the participation of local residents in school curriculum planning.

\section{COOPERATION WITH JICA - RURAL EDUCATION DEVELOPMENT PROJECT:}

The 3-year project "Rural Development Project with Community Participation" finished in September. We have promoted community-minded activities such as improvements to the school environment, activation of the libraries, education for pre-school children, traditional music band projects, and the extension of rice banks. An action team was organized in the Education Bureau of Svay Rieng province, which has taken over monitoring. In June, with assistance from Tokyo office staff, a final internal evaluation was carried-out and a report prepared.

\section{HUMAN RESOURCES DEVELOPMENT PROJECT:}

\section{(1) Japan-Cambodia Friendship Vocational Training Center}

In order to clarify the independent, selfhelp structure, our support was terminated in December 2003 and the center was transferred to the Education Bureau of Phnom Penh City.

\section{(2)Prey Konkhlar Skill Training Center (the former Battambang Training Center)}

The center continued tr aining in dressmaking, silkworm culture and fish farming. Support was terminated in March 2003, and the center transferred to the Education Bureau of Battambang province. 


\section{LAOS}

\section{OVERVIEW:}

This year will be an historical year for Laos because, for the first time since it joined ASEAN, it will take the chair at the summit and the foreign minister's meeting at the end of November. But the country is facing very serious problems that they have never experienced before such as a chronic shortage of government funds, the delayed payment of teacher's $\$ 15$ salary, the increasing gap between the rich and the poor, the growing gap between the cities and farming villages, environmental destruction, narcotics, street children, HIV and others.

In 2004, we will further tansfer authority of office management to the Laotian staff and try to increase the level of their ability. In the meantime, we will focus on public relations and fund raising, both locally and overseas.

\section{LIBRARY AND YOUTH ACTIVITIES:}

We constructed a provincial library in Savannaket district. After the opening, the library received many visitors, including many inspectors from the government and private institutes. The library is now a model library for the province.

Visitors to the young people's library on the first floor of the Vientiane office have also increased, and sometimes it is difficult to find a seat. The library in the office received 31,633 visits last year. They registered 2,049 new members. Children's books total 3,080 and books for youths to tal 4,410 . The total number of books has increased to 20,873 volumes.

We distributed 101 book-boxes, mainly in Savannaket province, and the total number of book-boxes distributed in the last 11 years is 1,377 in 12 provinces.

In cooperation with The Japan Foundation, we held two seminars to train Laotian writers, picture book painters, and editors. Further, in order to supplement the lack of picture books, we published three titles with 3,000 copies of each. It should be noted that 20 college students served as volunteers in the youth activities, which is rare for youths in Laos.

In 2004, we plan to continue construction of provincial libraries in more districts. We will try to complete the under-construction provincial library in Luang Prabang province, and also explore the possibility of constructing more libraries in Vientiane city and neighboring districts. We will also try to startour own mobile library project.

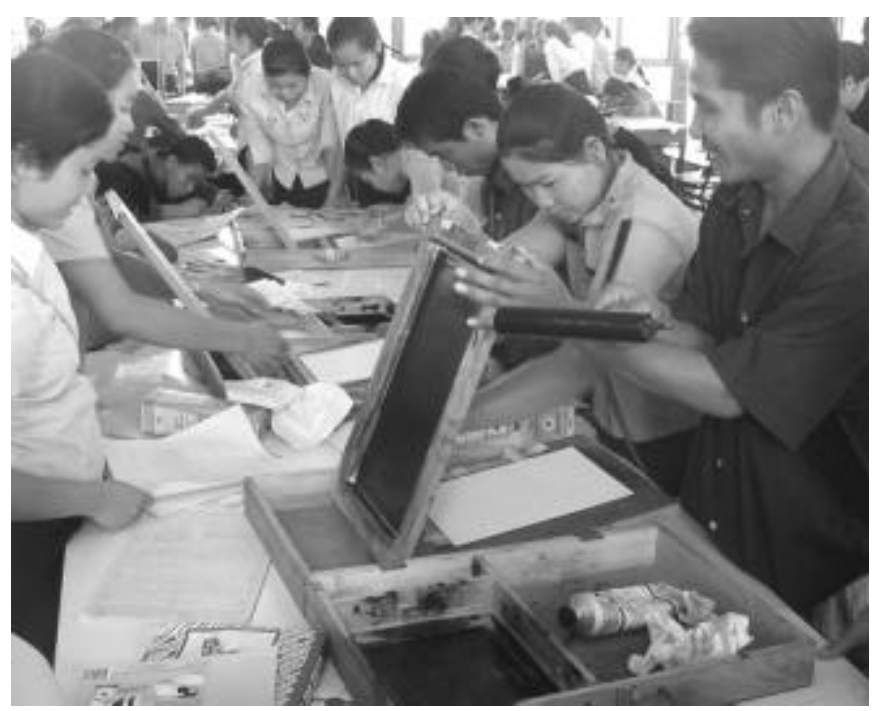

\section{ASIAN CHILDREN'S HOUSE ACTIVITIES:}

The partner agreement with JICHIRO (All Japan Prefectural and Municipal Workers Union) expired in March 2003. But we focused on holding seminars for the expansion of activities to preserve traditional Laotian culture and cultural pride, such as teaching 20 kinds of traditional dance and music. We also expanded children's house activities, primarily library activities.

The 828 members of the traditional culture activities, and the 869 members of library activities worked actively throughout the year. Consequently, the children's house has become a model for children's cultural centers throughout the country.

\section{ELEMENTARY EDUCATION TEACHING MATERIALS PROJECT:}

In 2003, we completed production and delivery of mimeograph printers to 8,120 schools all over Laos, and in December we held a ceremony commemorating the completion. Production of mimeograph printers at the Development Center of Teaching Materials in Vientiane has also finished. We provided mimeograph training at the teacher training schools in eight provinces throughout Laos. Further, we continued publication of class newspapers using mimeograph printers in Bolikhamsai province.

In 2004, we plan to record and publish a 10-year history of the mimeograph printer project. We will continue follow-up evaluations of the mimeograph printers, and will also continue mimeograph training at the teacher training schools.

\section{SCHOOL CONSTRUCTION WTH LOCAL HELP AND EDUCATIONAL SUPPORT:}

We constructed three primary schools and one kindergarten in Bolikhamsai province with the support of the local community, and we also held training sessions for teachers in the province. We have terminated activities at the Phonesy cluster school, Pak Kading, Bolikhamsai province and made an evaluation. We have also discussed the new educational support project in the southern province of Salavan with the government and provincial offices.

In 2004, using the evaluation of the Phonesy cluster school as a joint educational support project with the local community, we plan to construct three primary schools, a kindergarten and library in Bolikhamsai province and, for the first time, in Salavan province. On school construction, we will try to reduce construction costs further to meet the requirements of schools and villages. In the joint educational support project, we plan to create a teacher training system and exchange picture books within the school cluster, as well as revitalize the parents association.

\section{INTERNATIONAL INTERCHANGE AND SEMINAR:}

We have focused on internships, study tours, interchanges, and acceptance of inspectors and, as a consequence, visitor numbers have sharply increased. In 2003, we accepted 25 visiting groups and 165 individuals. We have carried out a survey on street children, who are increasing in Vientiane, and prepared a report. 12 children participated in the 8th Asian Children's Cultural Festival (held in Thailand).

In 2004, with the International Training Dept. taking a leading role, we plan to step up the internship, study tour, acceptance of inspectors and seminar projects. 


\section{AFGHANISTAN}

\section{OVERVIEW:}

In December 2003, the Grand National Conference (Loya Jirga) was convened, and on January 4 a new constitution was enacted. A general election is scheduled for 2004, and this year will be very important for ascertaining the future direction of the country. 2003 was a year with many vicissitudes such as, regular assaults on U.N. staff, ISAF and relief organizations following the aerial bombing of Iraq in March. Further, our activities were extremely restricted due to frequent power failures and the harsh natural environment. Despite such conditions, we had April openings of our office in Jalalabad and sub-offices in Peshawar and Kabul, in cooperation with Nejat Center (an Afghan NGO).

\section{ELEMENTARY EDUCATION IMPROVEMENT ACTIVITIES (Nangarhar Province)}

\section{(1) School construction:}

We built Takiya Garay primary school in Batikot district (completion due March 2004) with 8 classrooms, and a boys' primary school at Chardihi High School (completion due June 2004) with 13 classrooms. For construction of school buildings, we did not contract builders but instead organized our own construction team to procure building materials, design and carry out the construction work. It required a considerable amount of work but we were able to build school buildings with the participation of the local community. At present, the Ministry of Education only allows construction of school buildings of more than 12 classrooms and so, for the time being, we are bound to continue construction of large school buildings.

In 2004, we plan to construct one school building in each of the districts of Lal Pur, Batikot, Kot and Goshta with library and toilet and, if necessary, a well. When completed, we will distribute stationery and hold seminars on the use of toilets (to foster sanitation) and also a workshop on the maintenance and administration of the buildings.

\section{(2) Library project:}

\section{Workshops for teachers:}

In 2003, we focused on the mobile library and community library projects. In August, as the first step in the picture book project, we carried out a workshop by specialists, mainly for the staff.

In 2004, we plan to open workshops mainly in the four districts where school construction has already been decided upon and in Jalalabad city. After the workshop, we will distribute 170 picture books to each school. We also plan to invite specialists from Japan, as in the previous year.

\section{Mobile book-box project:}

To allow teachers to become familiar with the picture books and also to find out their reaction to them, we carried out the mobile book-box project on an experimental basis. Every book-box contained five copies each ofeight titles, totaling 40 picture books. In 2003, we distributed book-boxes to 20 schools (10 schools in Jalalabad city, 5 schools in Dara-I-Nur district, 4 schools in Batikot district and 1 school in Lal Pur district).

In 2004, we plan to carry out the project in Jalalabad city and the four districts where school construction is planned.

\section{Publication project of Pashtun language picture books:}

In 2003, we collected about 70 folktales and, through a selection by the Screening Committee of Picture Books for Publication (consisting of specialists in education and publishing), five titles were selected and published in March, totaling 1,000 copies.

\section{Operation of Community Library:}

In 2003, we established the library management system and, in order to survey the children's taste in picture books, we carried out a community library project on an experimental basis in Jalalabad city. The results were very favourable and we plan to continue the community library in 2004. At first, it was in one room of a private house but, considering the cultural tradition to separate males and females in public, we moved to new premises (3 rooms) in January 2004. Here children can read picture books anytime and, further, literacy classes in the Pashtun and Dari languages are provided for the children who cannot follow the lessons in class. Furthermore, the Provincial Bureau of Information and Culture send their staff here periodically and, in the future, we will consider transferring the operation.

\section{Setting up School Libraries: (new project in 2004)}

When constructing school buildings, we will set up a school library for the convenience of children and teachers, and also to show it as a model room and use it as a workshop for teachers of neighbouring schools. In each school library, 300 picture books will be stocked (Pashtun books: 20 titles x 5 copies, Iran Urdu books affixed with Pashtun translation: 10 titles $\times 5$ copies, books published by SVA: 10 titles $\times 10$ copies and Japanese books: 10 titles $\times 5$ copies).

\section{STREET CHILDREN SUPPORT ACTIVITIES (PESHAWAR, PAKISTAN)}

In 2003, the Afghan Children's Center (ACC) was established near Bord Market in Peshawar and commenced activities. Unlike activities at the refugee camps that cater to specific children, it is open to all children around Bord Market. It aims to not only protect the children but to also urge them to voluntarily participate in the operation of the center. At present, 130 children are registered at the center. It provides various classes such as literacy class (Dari and Pashtun), Afghan traditions, music, painting, arithmetic, handicrafts and others. It also provides reading of picture books and storytelling, health checks for the children by our medical staff and visits to the camps near ACC. From 2004, following the idea of Nejat Center, support activities for the street children will be shared. NejatCenter will be responsible for the administration, and SVA will be responsible for financial support and the education project.

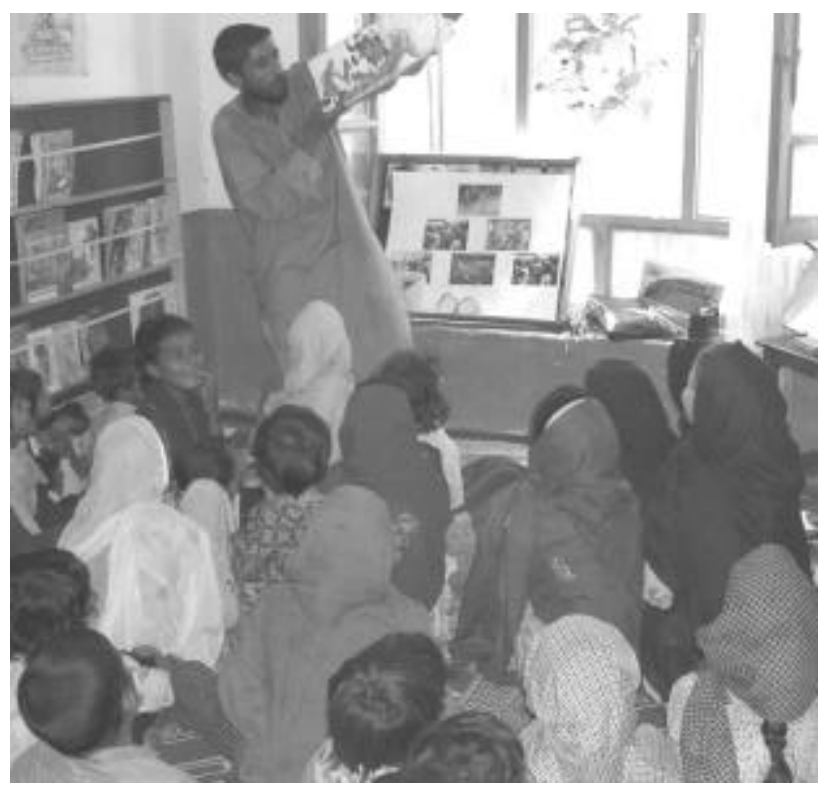




\section{MYANMAR (BURMESE) REFUGEES}

\section{OVERVIEW:}

In Myanmar (Burma), Gen. Khin Nyunt was named prime minister last August. He has proposed a "road map" for democratization but, so far, no concrete talks have eventuated. Under these circumstances, the number of refugees moving to Thailand is ever increasing and, in 2003, about 6,000 new refugees arrived.

In August 2003, support activities for the Myanmar refugee camps reached their third year. As always, this year we have endeavored to promote camp library use among even more camp residents, and to increase its function as a place for education and also a community center.

In 2004, we aim to further increase usage of the library, strengthen the management capabilities and organize a new secretariat system.

\section{LIBRARY ACTIVITIES:}

In 2003, we commenced library activities at the Ban Dong Yang Refugee Camp in Kanchanaburi province of northwest Thailand. This library was opened in July, and is the sixth camp benefiting from our activities. In March, the library in the Mae Kong $\mathrm{Ka}$ Refugee Camp that was washed away by a deluge in September 2002 was re-built, and a fourth library was opened in Mae Ra Ma Luang Refugee Camp.

In 2004, we plan to commence library activities at Tham Hin Refugee Camp in Ratchaburi province, which will be our seventh library. Further, we will build a library at he new campsite of Mae Kong Ka Refugee Camp. .

Number of library constructions to the end of 2003

\begin{tabular}{|c|c|c|}
\hline Province & Refugee Camp & No. of libraries \\
\hline \multirow{2}{*}{ Mae Hong Son } & Mae Kong Ka & 3 \\
\cline { 2 - 3 } & Mae Ra Ma Luang & 4 \\
\hline \multirow{3}{*}{ Tak } & Nupo & 2 \\
\cline { 2 - 3 } & Umpium & 3 \\
\cline { 2 - 3 } & Maela & 5 \\
\hline Kanchanaburi & Ban Dong Yang & 1 \\
\hline \multicolumn{2}{|c}{} & 18 \\
\hline
\end{tabular}

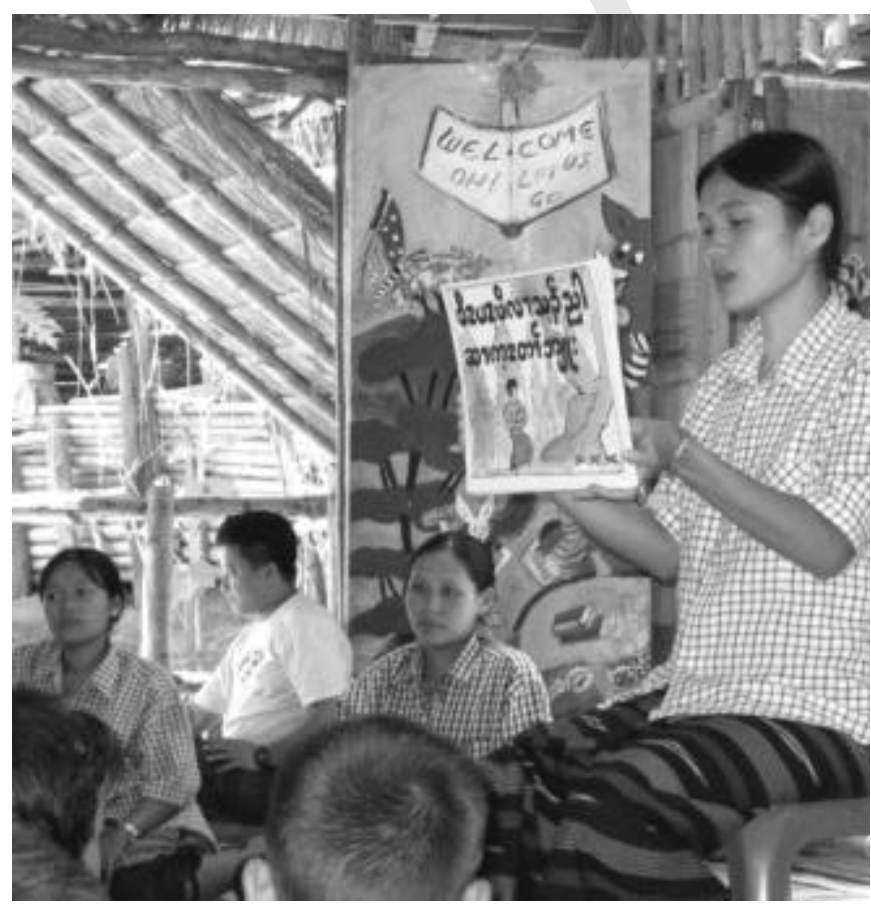

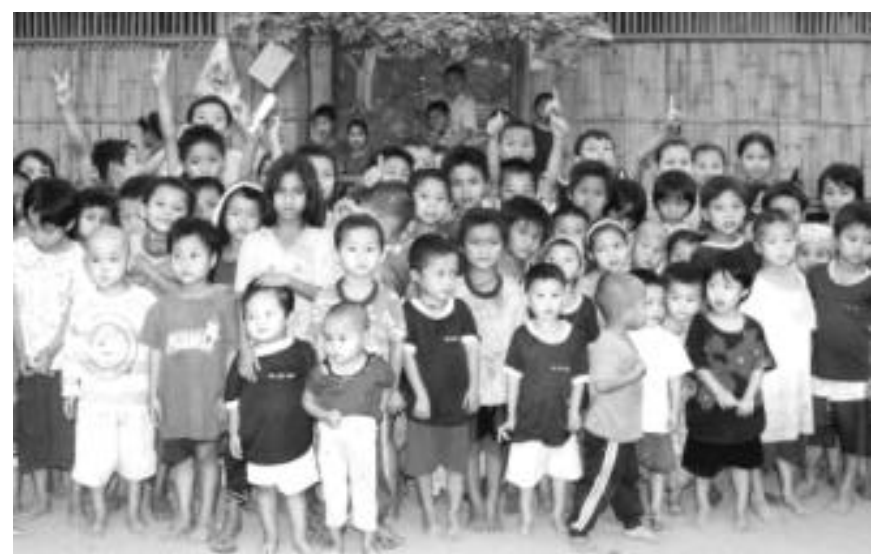

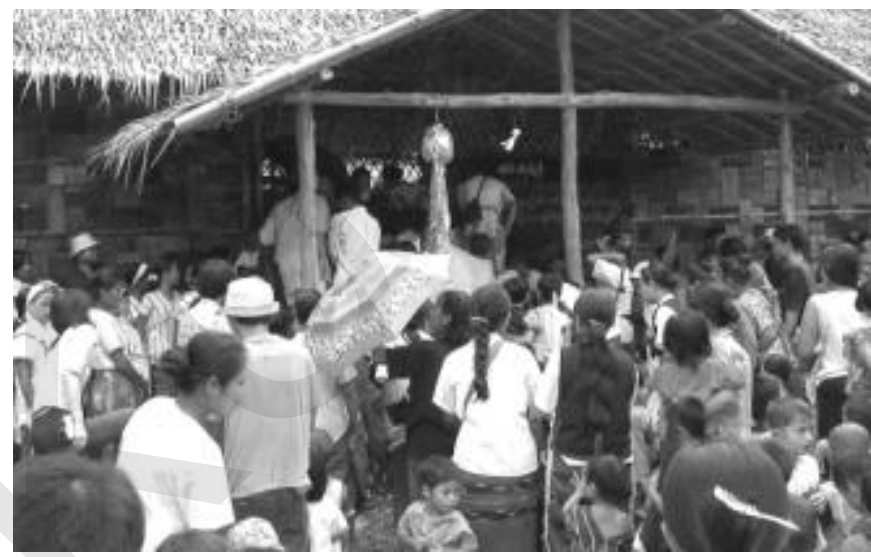

\section{PUBLICATION:}

In 2003, we distributed to each library 19 book titles for children, affixing translations in the Burmese and Karen languages, and books for adults mainly in Burmese. In 2004, we plan to distribute 20 titles of picture book with translations and, for adults, we plan to stock a greater number and variety of books.

\section{TRAINING FOR THE LIBRARY AND SVA STAFF:}

We organized training for the library staff every month. In addition, we have continued seminars on picture books since 2002 for the library staff. At Mae Sod, we also organized seminars for the combined library staffs of four refugees camps. We plan to continue the seminars in 2004.

\section{MIDTERM EVALUATION:}

At several refugee camps, we conducted midterm evaluations of library activities such as "Change of Children's Attitudes at Home". The survey was conducted among children, adults, nursery schools, primary school teachers and library staff, and the results will be reported to the library and library committee for future reference.

\section{CAMPAIGN TO SEND WNTER CLOTHING:}

The campaign, which started in 2001, finished in 2003 as scheduled. With the cooperation of regional support organizations in Japan, we collected 170,000 items of winter clothing, and they were distributed in nine refugees camps and neighboring, needy Thai villages at the end of December. Previously, the procedure to exempt import duty on the clothing took a lot of time, but this year prior arrangements with authorities have helped the process go smoothly and an import permit was granted. A monitoring tour is scheduled from the end of January 2004. 


\section{EMERGENCY RELIEF ACTIVITIES}

In 2003, earthquakes occurred in northern Miyagi prefecture at the end of July, and in souneastern Iran at the end of the year. We participated in the reliefactivities at both sites.

\section{VOLUNTEER CENTER FOR NORTHERN MIYAGI PREF. EARTHQUAKE:}

On July 26, an earthquake occurred in northern Miyagi prefecture. We dispatched a staff member to Nangocho, one of five damaged towns, to assist in setting up the Disaster Relief Volunteer Center. With enthusiastic cooperation from the staff of the Social Welfare Council and local volunteers, an autonomous management system was rapidly established to facilitate relief activities for the town's people.

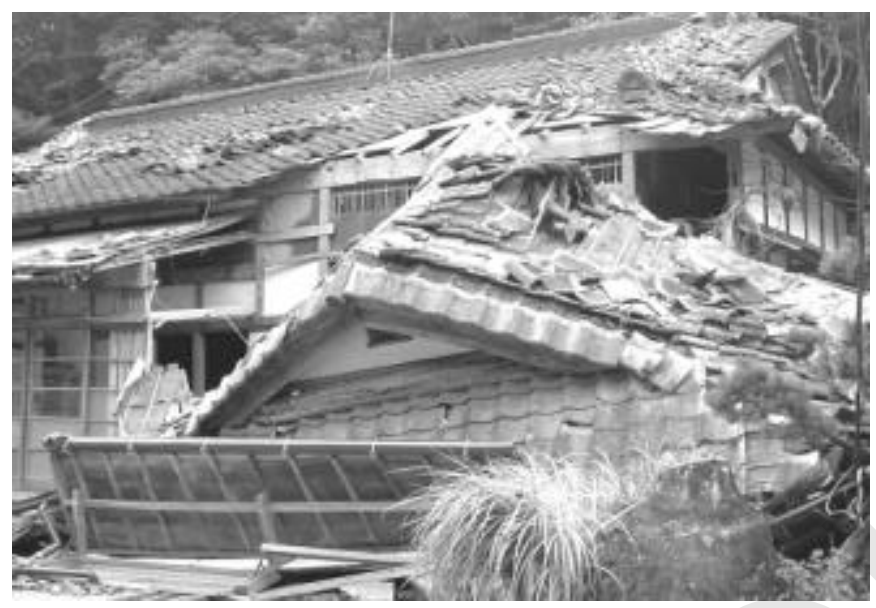

\section{RECONSTRUCTION AFTER GREAT EARTHQUAKE IN WESTERN INDIA:}

The support project for reconstruction of houses for the low-income earners and nursing facilities at Gujarat in western India, which has been carried out since 2002, has finished. We dispatched two staff members to the site for a final evaluation who confirmed the completion of the project.

\section{SUPPORT FOR VICTIMS OF DROUGHT IN WESTERN INDIA:}

Large-scale drought occurred for five consecutive years in the province of Gujarat. We received a request for support fromASAG, a local NGO with whom we worked at the times of the great earthquake in 2000 and the religious uprising in 2001. We donated one million yen, which was appropriated for the purchase and distribution of livestock feed, management of livestock shelters and control of water supplies.

\section{SUPPORT FOR CHILD VICTIMS OF EARTHQUAKE IN SOUTHEASTERN IRAN:}

On December 26, 2003, a great earthquake occurred in the city of Bam in southeastern Iran, and on January 6 we dispatched two staff members to survey the situation. They found that there were 5,000 children who had lost one parent and 1,800 children who had lost both parents. Thus, we decided to commence support activities, mainly for the children.

Activities planned for 2004 are: Reconstruction of an orphanage in Kerman city, capital of the province; Distribution of living necessities to the children of all orphanages in Kerman city; Provide temporary accommodation for a kindergarten reopened in Bam city, distribute living necessities and also provide training for the teachers.

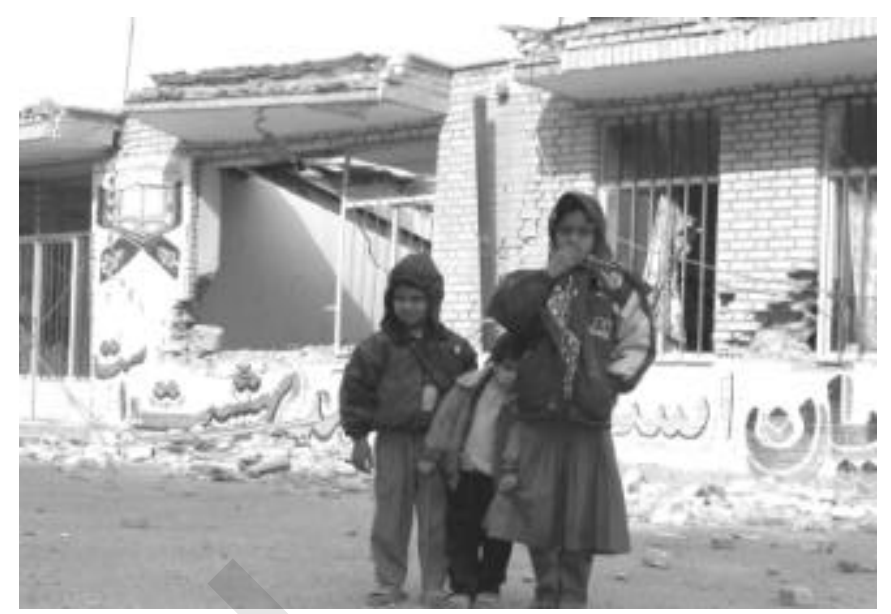

\section{OVERSEAS EMERGENCY RELIEF SYSTEM:}

The system for our overseas emergency relief campaign was reviewed and reinforced. Under the new system, the criteria for implementing primary action and the procedures for relief activities are better regulated. Task force members were also chosen.

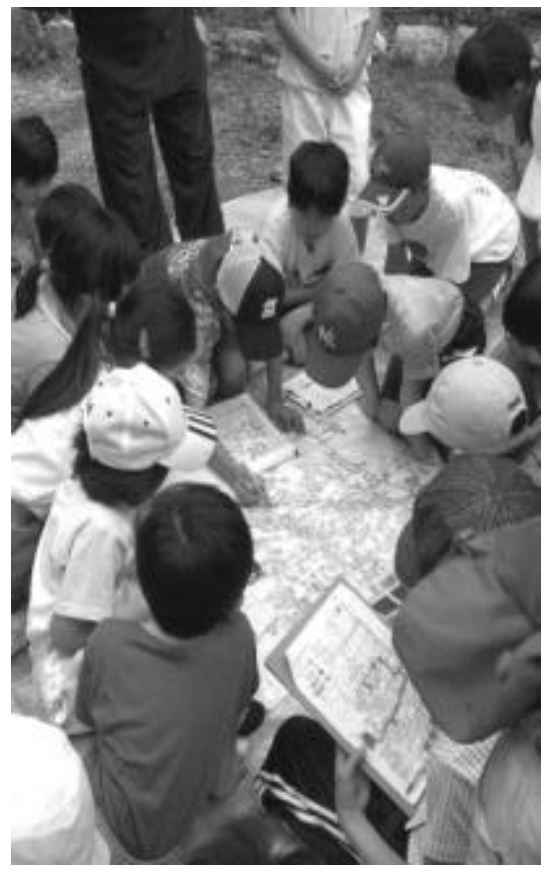

\section{"DISASTER PREVENTION CENTER" CAMPAIGN:}

Keeping in mind the regular occurrence of large-scale earthquakes, we have begun developing an educational program for children to cope with such a disaster, called Disaster Prevention Center, in cooperation with supporting temples and the National Sotoshu Youth Association. We have also established first stage guidelines for the secretariat in the event of an earthquake in the Tokyo area. 


\section{DOMESTIC ACTIVITIES}

\section{Activities Report}

\section{LINKAGE WTH MEMBERS AND SUPPORTERS:}

To encourage interchange among members and supporters, an assembly of nationwide supporters was held in Nagano in June, and an assembly of Kansai supporters was held in Osaka in October. Further, for the purpose of recruiting new members and supporters, a campaign was held utilizing thank-you cards, mailings and telephone calls that resulted in 130 new members. An additional 81 offices, shops and restaurants have agreed to place our donation boxes.

The campaign to send winter clothing to Myanmar (Burma) refugees has been successfully carried out for three years with cooperation from many regional support organizations.

\section{CRAFT AID:}

We have sought new marketing methods, and finished the year with a profit. On Recycle Book Aid, we have received support from individuals, business enterprises and trade unions. For the marketing of e-Mold (ecological tableware), we are investigating several marketing opportunities.

\section{SENDING BOOKS TO CHILDREN:}

Many supporters participated in the campaign, which has succeeded in sending 12,368 picture books to Cambodia and Laos. One notable development is that, with the collaboration of Bell Mark Educational Support Foundation, another 60 Japanese primary, middle and high schools have participated in the campaign. In addition to that 60, 112 schools have joined the campaign by raising their own campaign funds. For the screening and storing of the translated picture books, two supporting organizations "Handkerchief no Kai" of Chiba and "Onnajisora Network" of Nagano - have cooperated and, at the same time, many volunteers have cooperated everyday at the Tokyo office.

\section{PUBLIC RELATIONS:}

We posthumously published "Serenity on Earth", writings of the late Rev. Jitsujo Arima, and on December 10, SVA Day, a memorial lecture meeting was held. We have also continued making efforts to provide information to the public. Distribution of "Shanti", the SVA bulletin, was directed to various sources, depending on the topics of the issue. The SVA homepage has also been updated. Monthly Mail News has been published for business enterprises and the media.

\section{SUPPORT TO OVERSEAS ACTIVITIES:}

We have strived to obtain official donations, subsidies and grants, although due to a change in the regulations concerning the allocation of government funds, they took a considerable time to be granted. We have modified the guidelines in overseas projects. For the autonomy of the overseas offices, a working unit was organized to prepare guidelines but, after several studies, it was agreed to work out an intermediate vision first. The secretariat and the Board of Directors will discuss this matter further.

\section{NETWORKING:}

In January 2003, with SVA, Niwano Peace Foundation and AYUS taking a leading role, the "Buddhist NGO Network" was organized, and Rev. Matsunaga, president of SVA, was nominated to the representative committee. In collaboration with other NGO network organizations, it proposed advice or suggestions to the Ministry of Foreign Affairs and JICA. Further, SVA served as secretariat of the Japan NGO Network for Education (JNNE) and made efforts to raise the capabilities of Japanese NGOs, and proposed political advice on the educational cooperation by ODA.

\section{Activities Plan}

\section{LINKAGE WTH MEMBERS AND SUPPORTERS:}

We will proceed with data analysis of the members and, at the same time, will further focus on recruiting new members. In addition, we will facilitate remittances from members and supporters by promoting the new remittance method through convenience stores, introduced in December last year. We also plan to hold a supporters assembly in 2004. We wish SVA members and supporters in each region to link together, which leads to further linkage with other regions and, as a consequence, a significant network will be established.

\section{DOMESTIC CAMPAIGN:}

We will further step up ongoing activities such as Books for Children Campaign and Recycle Books Aid. At the same time, we will discuss new projects with supporters.

One new project we plan to launch is "Picture Books Contest." According to the plan, we will invite submissions of new picture books from Japan and other countries where SVA is located. Excellent books will be translated into the language of each country and distributed to all countries. Using this opportunity, we wish to promote the activities of SVA throughout the country in a more effective way.
In October, we will hold the "Asian Children's Cultural Festival" in Japan in cooperation with Nippon Television Network Culural Foundation. The festival has been held in overseas countries till now.

\section{PUBLIC RELATIONS:}

With the increase in members and supporters, their backgrounds are also more diversified. In order to meet this trend, we plan to upgrade our pamphlets, posters, home page and mail news. We also plan to strengthen our publicity. We plan to promote our activities in the temples, mainly through supporting temples.

\section{SUPPORT FOR OVERSEAS ACTIVITIES:}

We will prepare a 3-year Human Nurturing Program (2005-2007) based on the circumstances of each overseas office, and will discuss the possibility of moving toward autonomy. Further, we will follow up contacts with relevant organizations and positively try to obtain information and investigate the potential for future projects.

\section{NETWORKING:}

We will continue seminars and training through the network. We will serve as the secretariat of "Japan NGO Network for Education" (24 members). We will closely contact with other NGOs on the proposal of political advice to the Ministry of Foreign Affairs and JICA. 


\section{FINANCIAL REPORT (Years 2001-2004)}

\section{Income}

\begin{tabular}{|c|r|r|r|r|r|}
\hline Items/Year & \multicolumn{1}{|c|}{2001} & \multicolumn{1}{|c|}{2002} & \multicolumn{1}{c|}{$2003^{*}$} & 2004 Budget & \multicolumn{1}{c|}{$\%$} \\
\hline Membership Fees \& General Donations & $2,269,000$ & $2,060,000$ & $2,629,000$ & $2,824,000$ & 62 \\
\hline Donations for Emergency Relief Assistance & $1,203,000$ & 590,000 & 62,000 & 270,000 & 6 \\
\hline Support from General Programs & $1,406,000$ & 482,000 & 616,000 & 527,000 & 12 \\
\hline Support from Government \& UN Agencies & $1,069,000$ & 671,000 & 681,000 & 929,000 & 20 \\
\hline Total & $5,947,000$ & $3,803,000$ & $3,988,000$ & $4,550,000$ & 100 \\
\hline
\end{tabular}

\section{Expenditure}

\begin{tabular}{|l|r|r|r|r|r|}
\hline \multicolumn{1}{|c|}{ Items/Year } & \multicolumn{1}{c|}{2001} & \multicolumn{1}{c|}{2002} & \multicolumn{1}{c|}{$2003^{*}$} & 2004 Budget & \multicolumn{1}{c|}{$\%$} \\
\hline Thailand & 229,000 & 191,000 & 294,000 & 236,000 & 5 \\
\hline Cambodia & $1,825,000$ & 749,000 & 718,000 & 666,000 & 15 \\
\hline Lao P.D.R. & 490,000 & 265,000 & 380,000 & 502,000 & 11 \\
\hline Burmese Refugees & 147,000 & 178,000 & 235,000 & 286,000 & 6 \\
\hline Afghanistan & 521,000 & 75,000 & 217,000 & 400,000 & 9 \\
\hline Emergency Relief Assistance & 624,000 & 500,000 & 26,000 & 201,000 & 4 \\
\hline Domestic Programs & 796,000 & 567,000 & 813,000 & 886,000 & 20 \\
\hline Administration & $1,250,000$ & 973,000 & $1,503,000$ & $1,347,000$ & 30 \\
\hline \multicolumn{1}{|r|}{ Total } & $5,882,000$ & $3,498,000$ & $4,186,000$ & $4,524,000$ & 100 \\
\hline
\end{tabular}

*9 month financial report only, due to change in the SVA fiscal year

\section{Shanti Volunteer Association}

160-0015 Jibokaikan 2/3F 31 Daikyochou,

Shinjuku, Tokyo, Japan

Tel: (81) 35360-1233 Fax: (81) 35360-1220

Official website: http://www.sva.or.jp

E-mail: info@sva.or.jp 